\title{
Educação Especial: Perspectivas e Práticas pedagógicas no contexto Escolar
}

\author{
Aurilene Pereira de Moraes $^{1}$; Gislene Farias de Oliveira ${ }^{2}$
}

\begin{abstract}
Resumo: O presente artigo tem como base a questão da educação especial voltada para a inclusão escolar. Salientando que um olhar especial para dentro dos estabelecimentos regulares de ensino se faz necessário para que as leis e normas que garantem o direito de crianças e jovens com necessidades educacionais especiais sejam realmente cumpridas, efetivando assim a educação inclusiva. Para isso, o papel da família e da comunidade escolar é de suma importância, pois é na família que todos recebem a educação primeira, para somente depois poder conviver em sociedade. Os professores também são necessários nesse processo, pois se tornam mediadores entre os educandos diante das relações interpessoais com o meio em que estão inseridos. Por isso, o objetivo maior é conceituar e diferenciar a inclusão nas escolas, compreendendo suas formas e desafios na busca de auxiliar aos professores, às escolas, aos pais e à sociedade como um todo, para que a mesma e desenvolva com sucesso. Assim, foram levantadas algumas discussões teóricas a respeito da importância da escola ser inclusiva, incluindo o papel da família e do professor diante da inclusão escolar. Bem como compreender e que modo a inclusão vai se confirmando, e quais modificações precisam ser feitas para que haja a aceitação das pessoas incluídas, sinalizando assim as perspectivas de ensino e aprendizagem nesse novo cenário da educação brasileira. Concluiu-se, então, que a inclusão de crianças e jovens nas escolas regulares de ensino é um processo amplo, e que as aprendizagens significativas aparecem quando há respeito e envolvimento do todos para que seja construída a cidadania.
\end{abstract}

Palavras-Chave: Educação Especial. Inclusão escolar. Aprendizagem.

\section{Special Education: Perspectives and Pedagogical Practices in the School Context}

\begin{abstract}
This article is based on the issue of targeted special education for school inclusion. Stressing that a special look into the regular schools is necessary for laws and regulations that guarantee the right of children and young people with special educational needs are actually met, thus making effective inclusive education. For this, the family role and the school community is of paramount importance because it is the family that all receive the first education, for only then can live in society. Teachers are also required in this process, because they become mediators between the students on interpersonal relationships with the environment in which they live. Therefore, the main objective is to conceptualize and differentiate inclusion in schools, including their forms and challenges in search of help to teachers, schools, parents and society as a whole, so that it and successfully develop. So we were raised some theoretical discussions about the importance of the school to be inclusive, including the role of the family and the teacher before the school inclusion. And understand and how inclusion will be confirmed, and what changes need to be made so that there is acceptance of persons included, thus signaling the perspectives of teaching and learning in this new scenario of Brazilian education. It was concluded, therefore, that the inclusion of children and young people in mainstream schools teaching is a broad process and that significant learning appear when there is respect and involvement of everyone to citizenship is built.
\end{abstract}

Keywords: Special Education; School inclusion; Learning; Interrelations.

\footnotetext{
${ }^{1}$ Licenciada em Letras(ULBRA); Pós-Graduado em neuropsicopedagogia (UCAM);Mestrando em educação pela Anne Sullivan . E-mail: moraes.aurilene@bol.com.br;

${ }^{2}$ Psicóloga. Doutorado em Psicologia Social UFPB/PB. Pós doutorado em Ciências da Saúde - FMABC/SP. Professora Associada da Universidade Federal do Cariri - UFCA. E-mail: gislenefarias@ gmail.com.
} 
Id on Line Revista Multidisciplinar e de Psicologia

Id on Line Multidisciplinary and Psycology Journal

\section{Introdução}

Opresente artigo discorre sobre a questão da educação especial no Brasil, e está voltado para a inclusão nas escolas regulares. Ele busca também evidenciaras questões das práticas pedagógicas de qualidade que visem propiciar a aprendizagem e que busquem realmente a inclusão de crianças com deficiência na rede regular de ensino. O mesmo faz uma abordagem sobre os principais desafios da inclusão escolar na atualidade, que diante de muitas informações e leis voltadas para a inclusão, os mesmos ainda impedem que se tenha uma educação realmente inclusiva e de qualidade.

As escolas especiais, mesmo diante da suas dificuldades nos processos de inclusão, ainda assim, apresentam papéis importantes para as crianças e adolescentes com deficiências, pois elas oferecem atendimentos especializados, diferentes das escolas regulares que na maioria dos casos, não têm todos os recursos necessários para os que necessitam desse atendimento diferenciado.

Este artigo tem como objetivo, conceituar e diferenciar a inclusão, compreender suas formas e desafios, analisar leis que visam à inclusão dos portadores de necessidades educacionais especiais no ensino regular, no cenário das políticas públicas educacionais, com o propósito de auxiliar professores, escolas, pais e a sociedade como um todo.

Este artigo é fruto de uma pesquisa que objetiva, entre outras coisas, também entender como está o papel do professor diante desse desafio: uma escola para todos sem excluir e que deve preparar o educando para que ele possa viver com a multiplicidade, partindo do pressuposto que todos somos diferentes e por isso, precisa-se estar inseridos, respeitado e convivendo dignamente em sociedade.

O que justifica a escolha deste tema, educação escolar: um olhar para a inclusão, em parte é a minha preocupação social no que diz respeito à educação, assim como o meu interesse pelo referido assunto, o qual busco compreendê-lo de modo geral dentro do processo de inclusão das pessoas com deficiência na rede regular de ensino no Brasil, onde penso que precisamos rever valores, quebrar preconceitos e contemplar novos modelos pedagógicos diante de uma educação que seja realmente de direito e de fato para todos. 
Logo, é de fundamental importância que se observe ainda se existem condições necessárias de atendimento apropriado para que os educandos desenvolvam suas habilidades e de aprendizagens nesse processo de inclusão dos mesmos nas escolas.

A pesquisa sobre tema que originou este artigo se organizou em três tópicos dentro do seu referencial teórico. O primeiro relata um pouco sobre a inclusão no ambiente escolar. O movimento que é feito em busca de uma educação inclusiva está atrelado à ação política, social, cultural e pedagógica, desencadeada em defesa do direito de todos os educandos estudarem juntos, aprendendo e participando, sem que não haja nenhum tipo de discriminação.

Sendo assim, a educação inclusiva se apresenta como um novo olhar educacional tendo como base a concepção dos direitos humanos que congrega o direito de todos a uma educação igualitária independentemente de qual diferença se tenha. A este respeito nos diz a Secretaria de Educação Básica do Ministério da Educação (2012, p. 07):

\begin{abstract}
A inclusão da pessoa com deficiência no âmbito escolar é um debate atual que demanda a organização de várias propostas de trabalho, pelas especificidades inerentes à pessoa humana e pelas diversas barreiras existentes no contexto escolar. Ao se pensar essa inclusão é importante refletir acerca do que é incluir de fato, já que se trata de um tema polêmico do ponto de vista da prática educacional.
\end{abstract}

O segundo tópico vem mostrar a questão dos desafios da inclusão, as dificuldades das relações sociais das crianças especiais nas escolas regulares, as políticas públicas para a educação inclusiva, o papel do professor dentro deste processo. Mostra também a importância dos pais no processo da inclusão escolar e na aprendizagem dos educandos com necessidades especiais educacionais.

Compreende-se que as dificuldades enfrentadas no âmbito escolar mostram ainda mais a necessidade de se confrontar as práticas discriminatórias e se criar alternativas para que possam ser solucionadas. É nesse aspecto que a educação inclusiva assume espaço notório no debate acerca da sociedade moderna e na função da escola em combater exclusão o preconceito e promulgar a inclusão.

Diante das considerações propostas neste artigo, almeja-se contribuir com um novo olhar para a inclusão escolar, diante de tantos desafios encontrados em nosso atual contexto inseri-los na educação regular do nosso ensino tornando assim, modelos de escolas essenciais e que efetivamente incluam todos os educandos. 
Id on Line Revista Multidisciplinar e de Psicologia

Id on Line Multidisciplinary and Psycology Journal

\section{A Inclusão no Ambiente Escolar}

Sabe-se que é a política da inclusão escolar que proporciona o direito de toda criança poder frequentar a escola regular de ensino, independente de suas condições, sejam elas físicas, mentais ou sociais. Por isso, a educação escolar e as políticas públicas direcionadas para os educandos portadores de necessidades especiais têm sido motivos de muitos debates e questionamentos. As escolas especiais surgem em meados do século XX e mais tarde as classes ditas especiais foram também aparecendo dentro das escolas comuns, o que se observa hoje como uma deformidade pedagógica, pois desse modo, acabava por gerar situações seletivas, conceituando assim, formas de discriminação e classificando-os como "educandos com deficiência" e ducandos ditos "normais" na perspectiva de tentar integrá-los no convívio social.

Historicamente se sabe que nos anos 90, essa integração foi substituída pela inclusão, que propõe inserir essas crianças que apresentam necessidades educacionais especiais em classes comuns, juntos aos demais educandos, buscando assim, não mais classificá-los e nem discriminá-los, proporcionando a inclusão. Inclusão esta que prevê uma escola com políticas participativas, pautadas na cultura inclusiva, onde todos os profissionais da comunidade escolar são inseridos como colaboradores que devem agir entre si, ou seja, apoiam-se simultaneamente e aprendem uns com os outros a partir das reflexões sobre suas práticas docentes. $\mathrm{O}$ que podemos deduzir, conforme afirma (ALVES, 2009, p. 158) que:

\footnotetext{
Após a exclusão total das pessoas com deficiências, passamos pelo processo de integração, entendida aqui como um movimento individual do sujeito para ter acesso à participação nas escolas regulares, até chegarmos ao processo que estamos vivendo hoje, no qual há uma reestruturação das instituições educacionais comuns e da sociedade para acolher essas pessoas.
}

Diante disso, a escola tem encontrado dificuldades para fazer seu papel, pois construir esse modelo não é tão fácil como se imagina, já que nem todos os educandos se enquadram às condições estabelecidas pela escola. A educação especial é uma modalidade de ensino que perpassa todos os níveis e etapas de ensino, onde se realiza o atendimento educacional especializado, disponibilizando os serviços e recursos próprios desse atendimento e orienta os educandos e os profissionais ligados à educação, em especial os professores quanto a sua utilização nas turmas comuns do ensino regular. 
O atendimento educacional especializado não é tão simples como se pode imaginar,e por isso disponibiliza de enriquecimento curricular, que é o ensino de linguagem e códigos específicos de comunicação, que são ajudas técnicas e tecnológicas assistidas, dentre outras. Esse atendimento precisa estar estruturado com a proposta pedagógica do ensino comum no decorrer de todo o processo de escolarização.

Para que haja o processo de inclusão é preciso que todos na escola estejam engajados. Sabe-se que não é tarefa fácil quando se fala em mudanças para favorecer pessoas que foram excluídas e injustiçadas da sociedade e consequentemente na escola.

O Ministério da Educação define a educação inclusiva como diretriz para a transformação na estrutura da escola como uma política pública que assuma sua disseminação através do programa Educação Inclusiva: direito à diversidade, iniciada em 2003. Graças a isso, proporcionou-se um processo amplo de reflexão e discussão nos sistemas educacionais a respeito dessas formas tradicionais do pensar pedagógico e da quebra de uma concepção tradicional que determinava a relação entre as condições históricas, as desigualdades sociais, a questão da deficiência e da não aprendizagem.

Segundo Mittler (2000) “a escola inclusiva precisa como ponto de partida uma reforma integral nas escolas, reformular também o sistema existente e repensar completamente o currículo para alcançar as necessidades de todas as crianças". De acordo com o referido autor, a inclusão escolar não representa simplesmente passar o educando da escola especial para a escola regular, pois, ela requer uma mudança na mente e nos princípios para as escolas e para a sociedade em geral, porque implícito ao seu pensamento está a realização da diversidade.

A Declaração de Salamanca (1994), afirma que as escolas regulares com orientação inclusiva são os meios mais eficazes de combater atitudes discriminatórias, porém a educação está longe do ideal. O melhor atendimento escolar para pessoas com deficiência, como também para qualquer outra criança, é mesmo a escola regular.

\section{O Papel do Professor no Contexto de Inclusão}

O papel do professor no ambiente escolar é desenvolver um trabalho diferenciado, acolhendo e compreendendo cada um dos educandos de acordo com as suas necessidades. 
Quando o assunto é a inclusão escolar, precisam-se considerar aspectos relacionados principalmente com a formação do professor, pois eles devem estar preparados e seguros do que estão fazendo para poder trabalhar com o educando com necessidade educacional especial. Ainda em se tratando da inclusão escolar, devem-se considerar aspectos ligados à formação do professor, uma vez que este deve estar preparado e seguro para trabalhar com o educando com necessidade educacional especial.

A formação do professor tem que ser um processo constante, que vai além da sua prática com os educandos. Ele deve ter um trabalho interdisciplinar através de outros profissionais, dando apoio necessário para que o processo educacional aconteça de modo satisfatório. No entanto, é importante que haja uma valorização não somente do professor, mas também do saber de todos os profissionais da área educacional no processo de inclusão, afinal de contas, a questão não se limita à inclusão de um ou dois educandos, e sim, a todos aqueles que dela precisam. Daí a importância da dedicação de todos da escola, trabalhando em parceria uns com os outros, refletindo a cada instante e pondo em prática seus saberes para o bem de todos. Com isso, as escolas deverão se posicionar como autora de seus projetos pedagógicos, tendo como base as suas práticas, até porque, como se pode aferir na fala de MIRANDA e GALVÃO FILHO (2012, p.12):

\footnotetext{
Muitos professores e professoras acreditam que devem receber a preparação para trabalhar com estudantes com deficiência a partir de uma formação profissional que, vinda de fora (orientações, direção, estado), dê a eles autonomia para atuar. Mas também, se verifica que tais processos de formação adquirem sentido, na medida em que se articulam com os saberes que os educadores desenvolvem, tendo em vista as suas histórias de vida individual, as suas relações com a sociedade, com a instituição escolar, com os outros atores educativos e os lugares de formação.
}

É necessário que o professor utilize de um planejamento dinâmico e flexível que se molde de acordo com a necessidade e a capacidade de cada um dos seus educandos. O professor deve se situar como propositor, como mediador e como facilitador na organização pedagógica dos seus educandos, dentro de sala de aula, para ele possa conseguir uma boa interação com os educandos, no sentido dele poder realizar da melhor forma possível o seu trabalho, sempre em parceria mútua, incluindo a todos numa proposta pedagógica eficiente, que o mesmo consiga maneiras para uma melhor interação dos alunos, mesmo que a sua turma seja composta de níveis bem diferentes. 
Id on Line Revista Multidisciplinar e de Psicologia

Id on Line Multidisciplinary and Psycology Journal

Segundo Mantoan (1997), a inclusão escolar é um motivo para que a escola possa se inovar, proporcionando assim aos professores terem o privilégio de aprimorarem suas práticas pedagógicas.

Ao falarmos sobre a atuação do professor, é viável que aconteça uma ação em que todos da comunidade escolar venham a contribuir, sendo necessário que a escola ofereça os recursos necessários, bem como o apoio da equipe pedagógica que possam oferecer subsídios adequados para que

O professor como mediador deverá promover um ensino igualitário, uma vez que quando o assunto é a inclusão escolar não diz respeito apenas aos deficientes e sim também à escola, onde se deve promover a diversidade devido a sua singularidade, formando assim, cidadãos conscientes para a sociedade.

Ter acesso à educação e esta ser de qualidade e igualitária é um direito de todos e nós como professores precisamos fazer com que isto aconteça. No entanto, tal intento somente será possível através de capacitações bem planejadas e bem executadas, principalmente quando entra em cena a questão da inclusão escolar, visando justamente melhorar o atendimento igualitário e ainda por cima de qualidade, com a garantia de acesso e permanência na escola, precisando também se apoiar em outros princípios como a acessibilidade, locomoção e respeito. Contudo, o professor tem que ser visto como mediador e propagador de um mundo mais justo e igualitário, tornando então a sala de aula um ambiente propício ao ensino e aprendizagem eficientes.

\section{O Papel da Família no Processo de Inclusão Escolar}

Os pais contribuem efetivamente no processo de inclusão escolar quando atuam em parceria com a escola dentro do seu Projeto Político Pedagógico (PPP). Deste modo, os pais podem ser considerados também como mediadores do desenvolvimento educacional dos seus filhos e não apenas aqueles que os adaptam ao meio social como muito pensam. Por tanto, a escola precisa responder às expectativas dos pais, já que eles também têm dificuldades de entender como se dá esse processo de incluir seus filhos nessas escolas regulares. Muitos deles se perguntam como serão tratados os seus filhos que apresentam necessidades na escola, se 
Id on Line Revista Multidisciplinar e de Psicologia

Id on Line Multidisciplinary and Psycology Journal

sofrerão bullying, se serão discriminados ou "deixados de lado", se realmente aprenderão alguma coisa, se contribuirão e de alguma forma com a sociedade, Tudo isso vem à tona em suas mentes, e por isso a escola tem que estar preparada para lidar com essas indagações e poder dar respostas a todas estas questões. Somem-se a estas questões algumas posturas mal declaradas por pessoas da área da saúde, que inadequadamente colocam nas cabeças dos pais que têm filhos com algum tipo de problemática, que eles nunca serão aceitos como pessoas “normais", conforme nos atestam GALVÃO, MIRANDA, DIAZ (2009, p. 19):

\begin{abstract}
A integração visa à qualificação ou habilitação da pessoa com deficiência para que ela possa se integrar na sociedade. Parte de uma abordagem clínica, de um modelo médico da deficiência, no qual a discriminação ou desvantagem social é entendida como resultado da incapacidade da pessoa de desempenhar determinadas ações, ela própria causada por um problema do campo da saúde.
\end{abstract}

É de competência da escola, em parceria com a comunidade, atender às expectativas e às necessidades de todos apresentando propostas e resultados palpáveis que garantam o, à permanência e ao sucesso dos sujeitos com necessidades especiais nas escolas comuns da rede regular de ensino (BARBOSA, ROSINI E PEREIRA, 2007, p.457).

Então, para que o processo de inclusão escolar aconteça satisfatoriamente, deve-se começar pela própria família, lutando para que os seus direitos políticos sejam respeitados e se tornem realidade. Pais que apresentam um pensamento negativo sobre a inclusão escolar e por isso não levam os seus filhos com essas necessidades para as escolas regulares, muitas vezes achando melhor deixá-los nas escolas que só fazem o atendimento especializado, estão contribuindo para que a inclusão escolar tenha a sua viabilidade social emperrada.

Barbosa, Rosini e Pereira (2007) debatem a respeito de que se os pais tiverem atitudes positivas em relação à educação inclusiva, mais fácil e rápido será esse processo. Já outros veem de forma preconceituosa essa questão de incluir esses filhos nas escolas regulares e assim preferem que estudem em escolas especializadas, como já foi falado anteriormente, contribuindo ainda mais para que haja exclusão dos mesmos.

Com isso, é necessário que se faça um processo de conscientização da família, e assim a escola manter com ela uma boa relação. Isto é primordial, pois os pais são aqueles que convivem frequentemente com seus filhos com necessidades especiais e vão adquirindo mais 
Id on Line Revista Multidisciplinar e de Psicologia

Id on Line Multidisciplinary and Psycology Journal

saberes e práticas para lhes darem melhor com eles, sabendo que eles precisam desse apoio familiar para superar as dificuldades encontradas no caminho para poderem aprender.

Os autores Ferraz, Araújo e Ferreira (2010) também compactuam que uma relação sólida entre a família e a escola é fundamental para que a inclusão seja bem sucedida, e desta forma ela venha a corresponder às expectativas de ambos os lados, ou seja, da família e da escola.

A Declaração de Salamanca (1994) já relata a respeito da necessidade dessa parceria entre a família e a escola de modo geral na intenção de incluir esses alunos da melhor forma possível nas escolas regulares. Parceria esta que traga consigo maior apoio aos pais para que possam desempenhar seu papel diante de seu filho que apresenta necessidades educacionais especiais para que assim eles sejam parceiros diretos da escola no processo de ensino e aprendizagem.

\section{Considerações Finais}

A educação especial, no Brasil, já vem sendo discutida e trabalhada há décadas, mas o processo de inclusão nas escolas e na sociedade só se tornou concreto quando os educandos com necessidades especiais tiveram o direito de se matricularem na rede regular de ensino. Mas isso não é tão simples assim, pois não basta ter esse direito de se matricularem, mas terem as condições necessárias para estarem dentro das mesma se em condições de igualdade.

Percebe-se, então, que as diferenças dividirão os mesmos espaços e daí surgirão os conflitos internos. Sendo assim, as políticas públicas evidenciam que as escolas devem que estar preparadas para poderem trabalhar com esses novos anseios, perspectivas e dificuldades que a educação inclusiva requer. Porém, a realidade é que esses alunos não se adaptam assim tão fácil, pois existe ainda uma falta de preparo das escolas, como também falta de formação para os profissionais das mesmas, principalmente para o professor que tem um papel primordial no processo da inclusão à educação especial.

A Educação Inclusiva surge como um desafio em busca pela igualdade e a não a discriminação ao garantir o acesso de todos no processo educacional, reduzindo as diferenças, colaborando para acabar com o preconceito, e ainda por cima, visando um ensino e aprendizagem de qualidade. 
No entanto, para isso de fato aconteça a escola precisa se desdobrar, não somente inserindo no Projeto Político Pedagógico, como manda a Lei de Diretrizes e Bases da Educação no 9.394/1996, mas também, colocando em prática a questão da inclusão e flexibilizando o currículo. Ou seja, adaptando-o para que a escola possa atender as individualidades de acordo com as necessidades especiais de cada um que participa do processo educacional. Além do mais, apoiar-se numa avaliação de forma igualitária, que dê plena oportunidade de aprendizagem para todos no processo de ensino.

Além do professor e da escola de maneira geral, não podemos deixar de falar da contribuição da família, principalmente dos pais nesse processo de inclusão escolar, pois eles são os pioneiros na educação dos seus filhos. A relação família e escola é de fundamental importância para que os discentes com necessidades especiais educacionais possam se sentir valorizados por ambas as partes envolvidas neste processo, e assim poder se relacionar, aprender e ensinar dentro da escola e em casa.

Como já foi citado, o papel do professor se torna crucial, sempre trabalhando adaptando o currículo, fazendo um planejamento flexível já que o mesmo quando também recebe formações suficientes se torna uma peça fundamental, aquele que mesmo sendo difícil, fará com que o sujeito possa ser inserido na sociedade.

Então, para que as mudanças ocorram, é preciso que se faça uma sondagem daquilo que já foi construído de forma positiva e o que ainda precisa ser feito, pois não é porque estes educandos apresentam necessidades especiais que deverão estar à margem da sociedade, da escola, da família e da sociedade. Todos nós precisamos caminhar juntos, lançando sempre olhares especiais para a inclusão escolar dessas pessoas.

\section{Referências}

ALVES, Cristina Nacif. O coordenador pedagógico como agente do processo inclusivo. In: SANTOS, Mônica P. dos; PAULINO, Marcos M. (Org.). Inclusão em educação: culturas, políticas e práticas. São Paulo: Cortez, 2006. p. 83-106.

BARBOSA, A. J. G.; ROSINI, D. C. e PEREIRA, A. A. (2007). Atitudes parentais em relação à educação inclusiva. Rev. bras. educ. espec., vol.13, n.3, p. 457. 
Id on Line Revista Multidisciplinar e de Psicologia

Id on Line Multidisciplinary and Psycology Journal

BRASIL. Constituição da República Federativa do Brasil. 1998.

BRASIL. Lei de Diretrizes e Bases da Educação Nacional. Lei nº 9.394 de 20 de dezembro de 1996.

BRASIL.Secretaria de Educação Básica. Diretoria de Apoio à Gestão Educacional. Caderno de educação especial: a alfabetização de crianças com deficiência: uma proposta inclusiva / Ministério da Educação, Secretaria de Educação Básica, Diretoria de Apoio à Gestão Educacional. -- Brasília: MEC, SEB, 2012. [48] p.

DECLARAÇÃO DE SAlAMANCA. Princípios, Políticas e Prática em Educação Especial. Espanha, 1994.

FERREIRA, Julio Romero. Educação especial, inclusão e política educacional: notas brasileiras. In: RODRIGUES, David (Org.). Inclusão e educação: doze olhares sobre a educação inclusiva. São Paulo: Summus, 2006.

FERRAZ, C. R. A.; ARAÚJO, M. V. e FERREIRA, M. E. C (2010). Inclusão de crianças com Síndrome de Down e paralisia cerebral no ensino fundamental I: comparação dos relatos de mães e professores. Rev. bras. educ. espec., vol.16, n.3.

FERREIRA, M. E. C. Educação Inclusiva. Dp\&A: Rio de Janeiro, 2005.

GADOTTI, Moacir. História das Idéias Pedagógicas. 8. ed. São Paulo: Editora Ática, 2007 p.12.

GALVÃO, Neuma. C. S. S.; MIRANDA, Theresinha. G.; BORDAS, Miguel. A.; DIAZ, Feliz (Org.).Educação inclusiva, deficiência e contexto social: questões contemporâneas/, Theresinha Miranda, autores, Elias Souza dos Santos... [et al.]. - Salvador: EDUFBA, 2009. $354 \mathrm{p}$.

GIL, Antônio Carlos, 1946-. Como elaborar projetos de pesquisa. Antônio Carlos Gil. 4. ed. - São Paulo : Atlas, 2007.

MANTOAN, M. T. E. A Integração de Pessoas com Deficiências: Contribuições Para uma Reflexão Sobre o Tema. Memnion, Editora Senac: São Paulo, 1997.

MEC/SEESP Lei da Acessibilidade (Lei 10.098). Ministério da Educação. MENDES, E.G. $\boldsymbol{A}$ Educação Inclusiva e a Universidade Brasileira. Disponível em http://www.ines.org.br/paginas/revista/espaco18/Debate01.pdf. Acessado em 21/10/2015.

MIRANDA, Theresinha. Guimarães. GALVÃO FILHO, Teófilo Alves. (Org.) O professor e a educação inclusiva: formação, práticas e lugares. Salvador: EDUFBA, 491 p., 2012.

MITTLER, P. Educação Inclusiva: Contextos Sociais. Traduzido WindyzBrazão Ferreira. Editora Artmed: Porto Alegre, 2001. 
PADILHA, A. M. L. Dirigindo o olhar para a sala de aula e conhecendo José. 3 ed. São Paulo: Plexus, 2004.

GALVÃO, Neuma. C. S. S.; MIRANDA, Theresinha. G.; BORDAS, Miguel. A.; DIAZ, Feliz (Org.).Educação inclusiva, deficiência e contexto social: questões contemporâneas/,

Theresinha Miranda, autores, Elias Souza dos Santos... [et al.]. - Salvador: EDUFBA, 2009. $354 \mathrm{p}$.

Como citar este artigo (Formato ABNT):

MORAES, A.P.; OLIVEIRA, G.F. Educação Especial: Perspectivas e Práticas pedagógicas no contexto Escolar. Id on Line Revista Multidisciplinar e de Psicologia, Janeiro de 2017, vol.10, n.33, p.141-152. ISSN: 19811179 .

Recebido: 23/10/2016

Aceito: $24 / 11 / 2016$ 